\title{
Discrecionalidad en la promulgación de las leyes (Tribunal Constitucional)
}

\author{
Comentario de Valeria Lübbert Álvarez
}

\section{CONSIDERANDO ${ }^{1}$ :}

\section{$(\ldots)$}

Quinto: Conforme a los artículos $6^{\circ}$ y $7^{\circ}$ del Código Civil, las leyes solo tienen fuerza obligatoria una vez promulgadas en la forma dispuesta por la Constitución Política y publicadas, en conformidad a la ley.

El distingo entre los conceptos de promulgación y publicación solo surge entre nosotros con motivo de la reforma de los dos artículos aludidos, a través de la Ley $\mathrm{N}^{\circ}$ 9.400, de 6 de octubre de 1949, que fijó su texto actual.

Constitucionalmente, la promulgación de las leyes es una atribución especial y exclusiva del Presidente de la República, a quien incumbe "[c]oncurrir a la formación de las leyes con arreglo a la Constitución, sancionarlas y promulgarlas" (artículo 32, $\mathrm{N}^{\circ} 1^{\circ}$, de la Constitución). Complementa tal formulación el artículo 72, según el cual es el Presidente quien, en caso de aprobar un proyecto despachado por ambas Cámaras, "dispondrá su promulgación como ley". Hacen también referencia a la promulgación otras disposiciones de rango constitucional, como los artículos 73 y 67 de su texto.

Para Silva Cimma, "la promulgación no constituye un acto de colegislador, sino que un acto administrativo de aprobación” (Silva Cimma, Enrique: "El Tribunal Constitucional de Chile” 1971-1973, p. 95). Su objetivo, a juicio de Rosende, es "constatar la existencia de la ley y la exactitud de su texto" (Rosende Subiabre, Hugo: "La promulgación y la publicación de la ley”, Ed. Nascimento, Stgo., 1941, p. 140).

Pero esta visión no es unánime. Desde otro ángulo, hay quienes piensan que la promulgación es un acto de naturaleza legislativa. Si la ley no puede ser ejecutada sino en virtud de una orden del Jefe del Estado -afirman los partidarios de esta posición- es ella la que comunica a la ley la fuerza de ejecución, completándola y perfeccionándola. Siendo así, es incuestionable que la promulgación que contiene esta orden, es uno de los elementos esenciales del proceso de elaboración de la ley, de manera tal que, en tanto no haya promulgación, no hay propiamente ley. Es la opinión de los clásicos, en el derecho comparado, como Laband, Jellinek y Hauriou, citados por Rosende (ob. cit., pág. 33).

\footnotetext{
${ }^{1}$ Por su extensión, se ha omitido la parte expositiva del fallo y solo se han transcrito los considerandos esenciales. El texto completo se puede consultar en: http://www.tribunalconstitucional.cl/wp/ver.php? id=2527
} 
Sexto: Que, con todo, el tema no puede merecer mayores dudas en nuestro Derecho Constitucional. En efecto, cuando el artículo $32 \mathrm{~N}^{\circ} 1^{\circ}$ de la Constitución Política de la República refiere, como atribución especial del Presidente de la República, la de "[c]oncurrir a la formación de las leyes, sancionarlas y promulgarlas", diferencia claramente en el proceso de elaboración de esta clase de normas, entre la función de co-legislador -que se expresa en su concurrencia a la "formación de las leyes", a través de los instrumentos que el ordenamiento constitucional le reconoce, tales como la iniciativa de ley, las urgencias, el veto, etc.- y las funciones de sanción y promulgación. En ambos últimos casos, se trata de un ejercicio de potestad reglamentaria manifiestamente inserto en el entorno de su variable autónoma y fuera del dominio legal.

Aunque cercanas, la sanción y la promulgación no son idénticas. Sí resultan en el hecho simultáneas, "como ocurre cuando esta se presta explícitamente dentro del plazo en que el Presidente de la República puede formular observaciones, no cabe confundir ni siquiera en tal hipótesis la diversidad de ambos actos ni prescindir del análisis separado de la naturaleza y efectos de uno y otro" (Silva Bascuñán, Alejandro: "Tratado de Derecho Constitucional. T. VII, págs. 229-230). En tanto la sanción agrega el consentimiento del Presidente de la República "ahora en su carácter y responsabilidad de Jefe de Estado, a la decisión de los órganos colegisladores ... para dar fuerza y vigencia al texto resultante del cumplimiento del proceso formativo de la ley", la promulgación establece el texto auténtico de la ley, reconoce su fuerza obligatoria y la ordena cumplir (Autor y obra citados, págs. 229 y 230). Como acertadamente observa Corral, "[E]s claro que la promulgación o es un elemento constitutivo de la ley, en cuanto que esta respecto de su formación constitucional ya se encuentra con su estructura definitiva y perfecta, aun antes de ser promulgada. Pero ello no significa que ya tenga validez como norma jurídica, pues, a pesar de estar ya estructurada perfectamente como proposición normativa, no se ha intimado públicamente a sus destinatarios”. Lo que lo lleva a concluir que los procesos de promulgación y publicación no son "integrantes de la formación del texto legal, pero sí elementos que dan cumplimiento al requisito de cognoscibilidad de la ley ..." (Corral Talciani, Hernán: "De la ignorancia de la ley. El principio de su inexcusabilidad”, Ed. Jurídica de Chile, Santiago, 1987, pág. 278);

\section{(...)}

Vigésimo tercero: Que, entonces, la carga impuesta constitucionalmente al titular del Poder Ejecutivo es la de promulgar, con entera fidelidad, el texto auténtico aprobado por el Congreso Nacional, a través de sus dos Cámaras. Como hemos visto, la efectividad de ese proceder no ha sido puesta en duda, concentrándose el reproche en la desarmonía del título de la ley, que fue votado y aprobado en la instancia legislativa correspondiente, respecto del rótulo con que designó a esa misma norma el Presidente de la República, en ejercicio de una potestad discrecional, no regulada formalmente en nuestro ordenamiento; 
Vigésimo Quinto: Que el antecedente a tener en cuenta por el Presidente de la República para nominar la ley sometida a su anuencia, no obstante la discrecionalidad de su atribución, no puede ser otro que la autenticidad de su contenido. De esta manera, lo razonable sería que el acto promulgatorio representara un compendio o resumen, lo más fidedigno posible, de la ley sancionada, habida consideración que, en definitiva, aquélla va a ser conocida en la sociedad por el apelativo que le aplique el titular del Poder Ejecutivo al momento de ejercer su referida exclusiva atribución constitucional.

Bien es cierto que, por ser inherente a su naturaleza, las potestades de orden discrecional otorgan a sus titulares un ámbito de libertad que los habilita para escoger el momento -el cúando - y el contenido concreto, dentro de los límites legales, de la decisión aplicable. Mas ello no significa que esta clase de poderes jurídicos no sean controlables, como se predicaba en los estadios primarios del Derecho Administrativo.

Por el contrario, "la discrecionalidad exige el uso de un arbitrio razonable y, en donde éste no se dé, esto es, en donde no concurra, habrá arbitrariedad, ausencia de razonabilidad y, por ende, acto nulo, viciado, contrario a derecho por desproporcionado, inidóneo, ineficiente, inoportuno" (Soto Kloss, Eduardo., ob. cit., pág. 379);

\section{(...)}

Vigésimo sexto: Que la atribución discrecional de facultades de que goza el Presidente de la República para la elección de la suma del decreto promulgatorio, consagrada como una práctica que, en cuanto tal, no configura un deber vinculante, ha de ejercerse dentro de los límites que demarcan el interés público-elemento siempre reglado de los actos administrativos- y los principios generales del derecho, entre los cuales los de razonabilidad y proporcionalidad.

En tal escenario, parece manifiesto que al introducirse en el decreto supremo de promulgación de la Ley $\mathrm{N}^{\circ} 20.595$ la expresión tantas veces aludida - "Crea el Ingreso Ético Familiar..."-, expresamente retirada del nombre con que el ente parlamentario la designó-, el Ejecutivo adicionó un elemento, que podría inducir a confusión o desconcierto a los operadores jurídicos y aun a los académicos y estudiosos, toda vez que la Recopilación Oficial de Leyes de la República, que por imperativo del artículo 26 de la Ley Orgánica Constitucional de la Contraloría General de la República ( ${ }^{\circ}$ 10.336) es llamada a "recopilar y editar en forma oportuna y metódica todas las leyes, reglamentos y decretos de interés general y permanente, con sus índices respectivos", anota y registra habitualmente las leyes que se promulguen por el Ejecutivo, a través del Subdepartamento de Toma de Razón, según lo dispone el artículo 37, letra a), de la misma ley, con la denominación que le otorga este último poder del Estado;

Vigésımo séptimo: Que la adición al nombre del producto legislativo, efectuada por la vía de la promulgación por el órgano competente, si bien no podría originar una antinomia constitucional, porque la ley ha permanecido inalterable en el tenor que le dio el órgano parlamentario -que es lo único que le incumbe controlar a esta Magistratura 
Constitucional- se aleja de los términos en que se verificó el debate legislativo y de la explícita definición consensuada en el Senado en orden a excluir del nombre de la ley la expresión añadida en la denominación empleada por el promulgador. Tal comportamiento, lejos de ser caprichoso, revela una intencionalidad enderezada a provocar en los destinatarios de la norma una percepción de su alcance y sentido más allá de la realidad de su verídico y más acotado contenido.

En ese escenario, este Tribunal Constitucional no podría sino representar la persistente actitud de preservar, en el imaginario colectivo, una denominación que, sin sustituir la ideada por el legislador parlamentario, está llamada a erigirse en signo de identidad de la ley. Se arriesga así crear en los destinatarios de la norma un sentimiento de incertidumbre que, de perseverarse en la línea denunciada en el reclamo conocido en autos, podría generar efectos no deseables en el proceso de identificación de las normas legales, con consecuencias inconvenientes en la perspectiva de la técnica legislativa.

La reseñada consecuencia, no relevante en clave constitucional, amerita empero un claro y definido llamado de atención hacia la fórmula promulgatoria aplicada en el caso de la especie, que no debería repetirse en lo sucesivo, a fin de resguardar la pureza, transparencia y racionalidad del proceso legislativo en su conjunto, así como los principios de buena fe y deferencia razonada, que deben presidir las relaciones entre los órganos del Estado.

Y TENIENDO PRESENTE lo prescrito en los artículos 93, $\mathrm{N}^{\circ} 8^{\circ}$ de la Constitución Política de la República y 105 a 108 de la Ley Orgánica Constitucional del Tribunal Constitucional, $\mathrm{N}^{\circ} 17.997$, de 1981,

\section{SE DECLARA:}

Que SE RECHAZA el requerimiento deducido a fojas 1, y, en consecuencia, la promulgación del proyecto de ley reclamado es correcta y se ajusta, por tanto, a los términos de la Constitución.

Se previene que los Ministros señores Marcelo Venegas Palacios e Iván Aróstica Maldonado dejan constancia de que, si bien concurren a rechazar el requerimiento de fojas 1 , no suscriben los considerandos $25^{\circ}, 26^{\circ}$ y $27^{\circ}$ de la sentencia.

Acordada con el voto en contra de los Ministros señores Raúl Bertelsen Repetto (Presidente), Carlos Carmona Santander, José Antonio Viera-Gallo Quesney y Gonzalo García Pino quienes estuvieron por acoger el requerimiento.

\section{COMENTARio}

En votación dividida, el Tribunal Constitucional se ha aproximado a dos cuestiones fundamentales sobre la promulgación de las leyes. Por un lado, cuál es la naturaleza de la promulgación. Por otro, cuál es la extensión de la potestad promulgatoria del Presidente de la República y del control que sobre esta compete al Tribunal Constitucional, de conformidad al $\mathrm{N}^{\circ} 8$ del artículo 93 de la Constitución. 
Respecto de la naturaleza de la promulgación, la sentencia concluye que aquella no es legislativa. Por el contrario, se trata de un acto de naturaleza administrativa de resorte exclusivo del Presidente de la República, que no elimina ni agrega nada al acto legislativo. El Presidente se limita a dar fe de lo aprobado por el Congreso, mandarlo publicar y ordenar cumplir.

Mientras que en el Estado monárquico la promulgación se identificaba con el acto legislativo, en el Estado moderno se consolida como un acto administrativo que se limita a constatar y hacer público lo acordado por el Congreso.

Respecto de la discrecionalidad del Presidente sobre la promulgación y el ámbito de control que le corresponde al Tribunal Constitucional, el voto de mayoría no es tan claro. Es más, las conclusiones a las que se llega en esta materia contradicen aquellas que en un principio se enuncian respecto de la naturaleza de la promulgación.

La sentencia distingue entre el acto mismo de la promulgación -cuestión que denomina de fondo-, y el decreto supremo en que esta se contiene -cuestión que denomina de forma-. Enseguida, concluye que no corresponde al Tribunal Constitucional controlar la forma del decreto supremo, sino solo el acto mismo de la promulgación (c. $\left.18^{\circ}\right)$. El Presidente cumple con promulgar el "texto que constitucionalmente corresponda", de conformidad al artículo $93 \mathrm{~N}^{\circ} 8 \mathrm{CPR}$, simplemente con la transcripción exacta del texto íntegro aprobado por el Congreso, con independencia del título que se le dé a la ley en el decreto promulgatorio. La configuración del decreto promulgatorio, en todo lo que no sea la transcripción íntegra y exacta del texto, posee "componentes de segundo orden" y "escrituraciones menores" (c. $19^{\circ}$ ) sobre las cuales el Presidente tiene discrecionalidad. Entre estas escrituraciones menores, a juicio del voto de mayoría, estaría el título de la ley.

El título de la ley, que el Tribunal califica de irrelevante, fue materia de enorme discusión durante la tramitación de la Ley N $\mathrm{N}^{\circ}$ 20.595. En efecto, luego de varias indicaciones, se acordó la denominación "Establece bonos y transferencias condicionadas para las familias de pobreza extrema y crea subsidio al empleo de la mujer", señalándose que no correspondía utilizar la denominación "Ingreso Ético", pues esta se refería propiamente a un ingreso y no a un beneficio directo como lo es esta nueva fórmula de entrega de beneficios ya considerados en el programa Chile Solidario.

Frente a la voluntad final del Congreso, el Presidente de la República no vetó el proyecto para imponer la denominación que le parecía más adecuada. Más tarde, en la promulgación, el Presidente simplemente impuso su voluntad, denominando a la ley como "Crea el ingreso ético", en circunstancias que dicha denominación fue expresamente rechazada por el Congreso.

El voto de mayoría señala que esta actuación del Presidente se enmarca dentro de la discreción que le corresponde, ajustándose a una exigencia de "razonabilidad" (c. $25^{\circ}$ y $26^{\circ}$ ).

No se explica en la sentencia qué puede tener de razonable la denominación del decreto promulgatorio dada en este caso, que se opone expresamente al contenido de la ley y a la voluntad expresa del Congreso que concurrió a aprobarla.

Por otra parte, concluir que el Presidente actuó razonablemente y dentro del margen constitucional resulta contradictorio con lo que la misma sentencia explica 
en otros considerandos. Se señala que "lo razonable sería que el acto promulgatorio representara un compendio o resumen, lo más fidedigno posible, de la ley sancionada, habida consideración que, en definitiva, aquella va a ser conocida en la sociedad por el apelativo que le aplique el titular del Poder Ejecutivo" (c. $25^{\circ}$ ), cuestión que no ocurre en el caso. ¿Cómo se explica que el Tribunal haga un llamado de atención al Presidente de la República aduciendo que una promulgación de este tipo "no debería repetirse en lo sucesivo, a fin de resguardar la pureza, transparencia y racionalidad del proceso legislativo en su conjunto" (c. $27^{\circ}$ ) y a la vez argumente que este actuó razonablemente?

Esta noción de discrecionalidad limitada por la razonabilidad operó como criterio decidor de la sentencia. Sin embargo, solo fue compartida por tres de los cinco ministros que conformaron el voto de mayoría, pues dos de ellos hicieron prevención al respecto indicando no compartir tales argumentos.

Si la promulgación "establece el texto auténtico de la ley, reconoce su fuerza obligatoria y la ordena cumplir” (c. $6^{\circ}$ ), entonces, la denominación del decreto o título de la ley es relevante pues forma parte esencial de la promulgación. Aquello que se enuncia como aprobado y se ordena cumplir, no puede ser individualizado de forma errónea. Mucho menos de forma abiertamente opuesta a la voluntad del Congreso.

Por lo demás, como indica el voto disidente, en la actualidad toda ley se identifica por su nombre y su número (c. $7^{\circ}$ ) y no cabe hacer un distingo entre el nombre asignado en el decreto supremo promulgatorio y el del proyecto de ley propiamente tal, sobre todo si se tiene en consideración que la ley es identificada por el nombre del decreto que ordena su promulgación (c. $\left.11^{\circ}\right)$.

El contrapeso que el Tribunal identifica para tamaña atribución presidencial resulta casi ingenuo: si bien el Presidente puede darle cualquier nombre a la ley, dicho nombre es irrelevante (c. $22^{\circ}$ y $24^{\circ}$ ). Con esto, se torna sin sentido el acto mismo de la promulgación y prácticamente lo confunde con la publicación.

Esta es la primera sentencia sobre esta materia. Si bien el voto de mayoría describe la promulgación como un tema que no puede merecer mayores dudas en nuestro Derecho Constitucional, la presente sentencia más que aclarar, genera interrogantes. Lo cierto es que será la Contraloría la que irá definiendo los criterios por los que debe regirse la promulgación. 